\title{
Long-term Efficacy of Trilostane for Cushing's Syndrome due to Adrenocorticotropin-Independent Bilateral Macronodular Adrenocortical Hyperplasia
}

\author{
Yoshinari Obata, Yuya Yamada, Megu Yamaguchi Baden, Yoshiya Hosokawa, Kenji Saisho, \\ Sachiko Tamba, Koji Yamamoto and Yuji Matsuzawa
}

\begin{abstract}
A 66-year-old man with Cushing's syndrome due to adrenocorticotropin-independent bilateral macronodu-

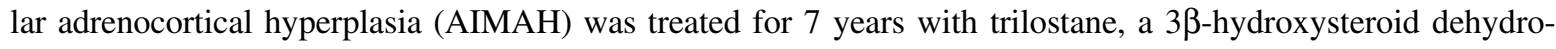
genase inhibitor. Administration of trilostane reduced the serum cortisol level to around the upper limit of normal for 7 years, and symptoms of excessive glucocorticoid production (such as moon face and obesity) were gradually improved. On the other hand, the size of both adrenal glands gradually increased despite treatment with trilostane. Though trilostane therapy could not prevent adrenal growth, it did suppress cortisol secretion over the long term, so it might be a reasonable option for AIMAH in addition to adrenalectomy.
\end{abstract}

Key words: adrenocorticotropin-independent bilateral macronodular adrenocortical hyperplasia (AIMAH), Cushing's syndrome, trilostane

(Intern Med 50: 2621-2625, 2011)

(DOI: 10.2169/internalmedicine.50.5578)

\section{Introduction}

Adrenocorticotropin-(ACTH) independent bilateral macronodular adrenocortical hyperplasia (AIMAH) is a rare disorder characterized by bilateral macronodular hyperplasia of the adrenal glands and increased cortisol production with subclinical or overt Cushing's syndrome, depending on the level of cortisol secretion $(1,2)$. Bilateral total adrenalectomy and lifetime steroid hormone replacement is the standard treatment for Cushing's syndrome due to AIMAH (2-4). Thus, there have been no reports on the longterm medical treatment of these patients.

Here we report a patient with Cushing's syndrome due to AIMAH who was treated for 7 years with trilostane, which inhibits the synthesis of cortisol by competitive and revers-

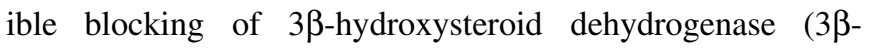
HSD) (5). This case may suggest a possible new approach to the management of Cushing's syndrome due to AIMAH.

\section{Case Report}

The details of the history of this patient up to the development Cushing's syndrome have been reported previously (6). In 1993, a 49-year-old man who had been treated for hypertension was referred to our hospital for the treatment gallstone colic. Bilateral nodular enlargement of the adrenal glands was found incidentally by abdominal computed tomography (CT). He had no signs of Cushing's syndrome. Despite a normal serum cortisol level, the plasma ACTH level was suppressed below the detection limit and the diurnal rhythm of cortisol was lost (Table 1). We could not perform dexamethasone suppression test at that time. Cholecystectomy and partial removal of the right adrenal gland were performed. Histological examination of the resected adrenal tissue revealed findings compatible with AIMAH. From these results, we strongly suspected subclinical Cushing's syndrome due to AIMAH.

After that, the patient slowly developed a typical Cushingoid appearance and his blood pressure became difficult to 
Table 1. Endocrinological Data

\begin{tabular}{cccccccc}
\hline & Normal range & 1993 & 2000 & 2005 & 2006 & 2007 & 2010 \\
\hline BMI & & 23.4 & 26.4 & 26.0 & 23.9 & 22.7 & 20.4 \\
Plasma ACTH $(\mathrm{pg} / \mathrm{mL})$ & $7.2-63.3$ & $<3.0$ & 3.0 & 3.0 & 5.0 & 5.0 & $<2.0$ \\
Serum Cortisol $(\mu \mathrm{g} / \mathrm{dL})$ & $4.0-18.3$ & 14.8 & 22.4 & 9.9 & 15.3 & 10.8 & 14.2 \\
Diurnal rhythm of cortisol & & vanished & vanished & vanished & $\mathrm{ND}$ & vanished & $\mathrm{ND}$ \\
PRA $(\mathrm{ng} / \mathrm{mL} / \mathrm{hr})$ & $2.4-21.9$ & $<0.1$ & 0.9 & 1.0 & 1.2 & $\mathrm{ND}$ & $\mathrm{ND}$ \\
Serum Aldosterone $(\mathrm{ng} / \mathrm{dL})$ & $3.0-15.9$ & 7.0 & 2.9 & 1.0 & 18.0 & $\mathrm{ND}$ & $\mathrm{ND}$ \\
DHEA-S $(\mathrm{ng} / \mathrm{mL})$ & $1300-1600$ & $\mathrm{ND}$ & 144 & 495 & 583 & 43 & $\mathrm{ND}$ \\
Urinary 17-OHCS $(\mathrm{mg} /$ day) & $3.1-8.7$ & 5.1 & 14.6 & 15.0 & $\mathrm{ND}$ & 5.8 & $\mathrm{ND}$ \\
Urinary 17-KS $(\mathrm{mg} /$ day) & $4.2-13.6$ & 2.1 & 5.2 & 13.0 & $\mathrm{ND}$ & 7.0 & $\mathrm{ND}$ \\
Urinary FC $(\mu \mathrm{g} /$ day) & $30-150$ & $\mathrm{ND}$ & 320.0 & 170.0 & 70.9 & 29.9 & $\mathrm{ND}$ \\
\hline BMI: body
\end{tabular}

BMI: body mass index. PRA: plasma renin activity.

DHEA-S: dehydroepiandrosterone-sulfate.

17-OHCS: 17-hydroxycorticosteroids. 17-KS: 17-ketosteroids.

FC: free cortisol. ND: not determined

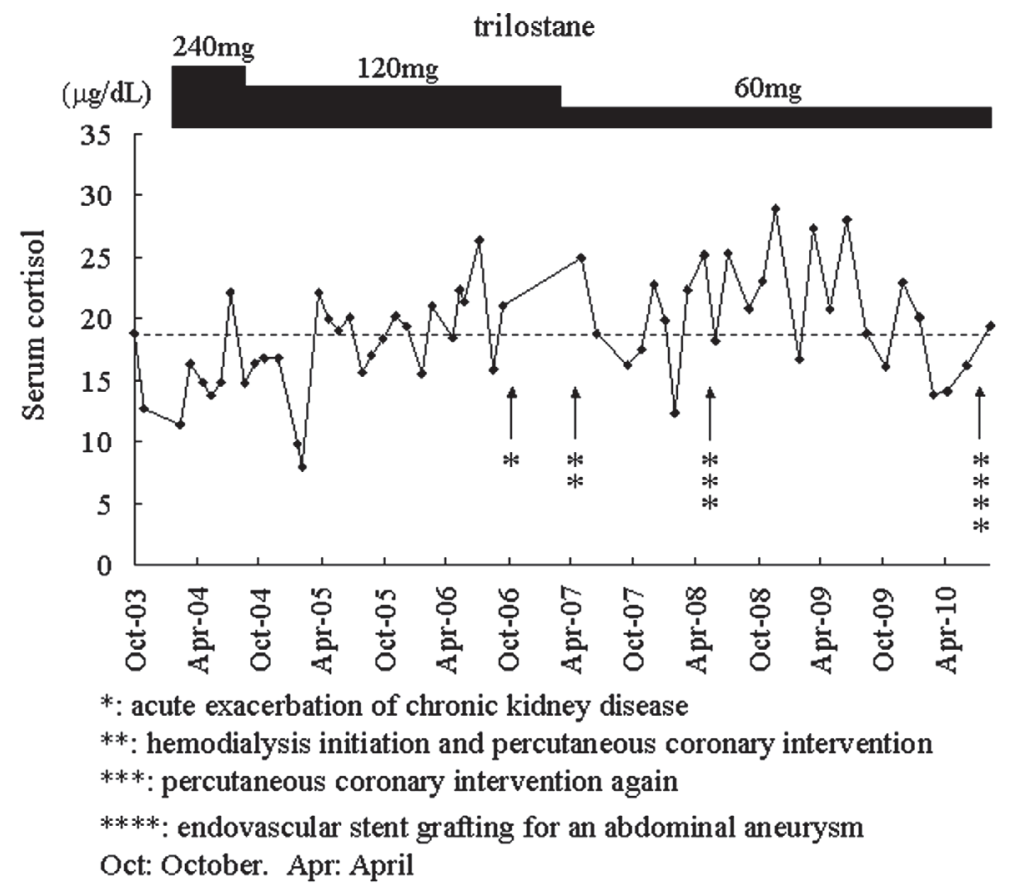

Figure 1. The clinical course and changes of the serum cortisol level, which was measured at his outpatient visits over 7 years. We started treatment with trilostane from December 2003 and reduced the dose gradually depending on renal function. Broken line represents upper limit of normal.

control, but he did not show glucose intolerance or electrolyte abnormalities. He was admitted to our hospital again in 2000. His serum cortisol level was above the normal range and plasma ACTH was suppressed throughout the day (Table 1). Both a low dose $(1 \mathrm{mg})$ and a high dose $(8 \mathrm{mg})$ of dexamethasone did not suppress the serum cortisol level on the next morning. Because these findings indicated overt Cushing's syndrome due to AIMAH, we recommended bilateral total adrenalectomy, but he refused surgery. Therefore, we started to treat him with trilostane, a $3 \beta$ -

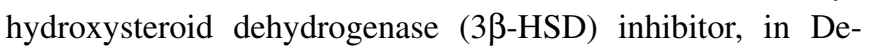
cember 2003.

The clinical course and changes of the serum cortisol level, which was measured at his outpatient visits in the midmorning or early afternoon over the next 7 years are shown in Fig. 1. Renal function was impaired at the first visit [in 1993; serum creatinine $(\mathrm{Cr}) 1.9 \mathrm{mg} / \mathrm{dL}$, probably due to nephrosclerosis in addition to left renal atrophy, and it gradually deteriorated thereafter. He was admitted with acute exacerbation of chronic kidney disease in October 2006 (serum Cr $5.18 \mathrm{mg} / \mathrm{dL}$ ) and hemodialysis was started for end-stage renal disease in April 2007 (serum Cr 10.69 $\mathrm{mg} / \mathrm{dL}$ ). As his renal function declined, we reduced the dose of trilostane from the initial dose of $240 \mathrm{mg} /$ day to $120 \mathrm{mg}$ / day in August 2004 (serum Cr $2.3 \mathrm{mg} / \mathrm{dL}$ ) and then to 60 mg/day in February 2007 (serum Cr 6.16 mg/dL), because trilostane is primarily eliminated by renal excretion. In 2007, ischemic heart disease was diagnosed and he underwent percutaneous coronary intervention in 2007 and 2008. In April 2010, abdominal aortic aneurysm was diagnosed and he underwent endovascular stent grafting. Serum cortisol levels (measured at his outpatient visits) have remained around the upper limit of normal for 7 years (Fig. 1).

Sequential changes of his body mass index and endocri- 

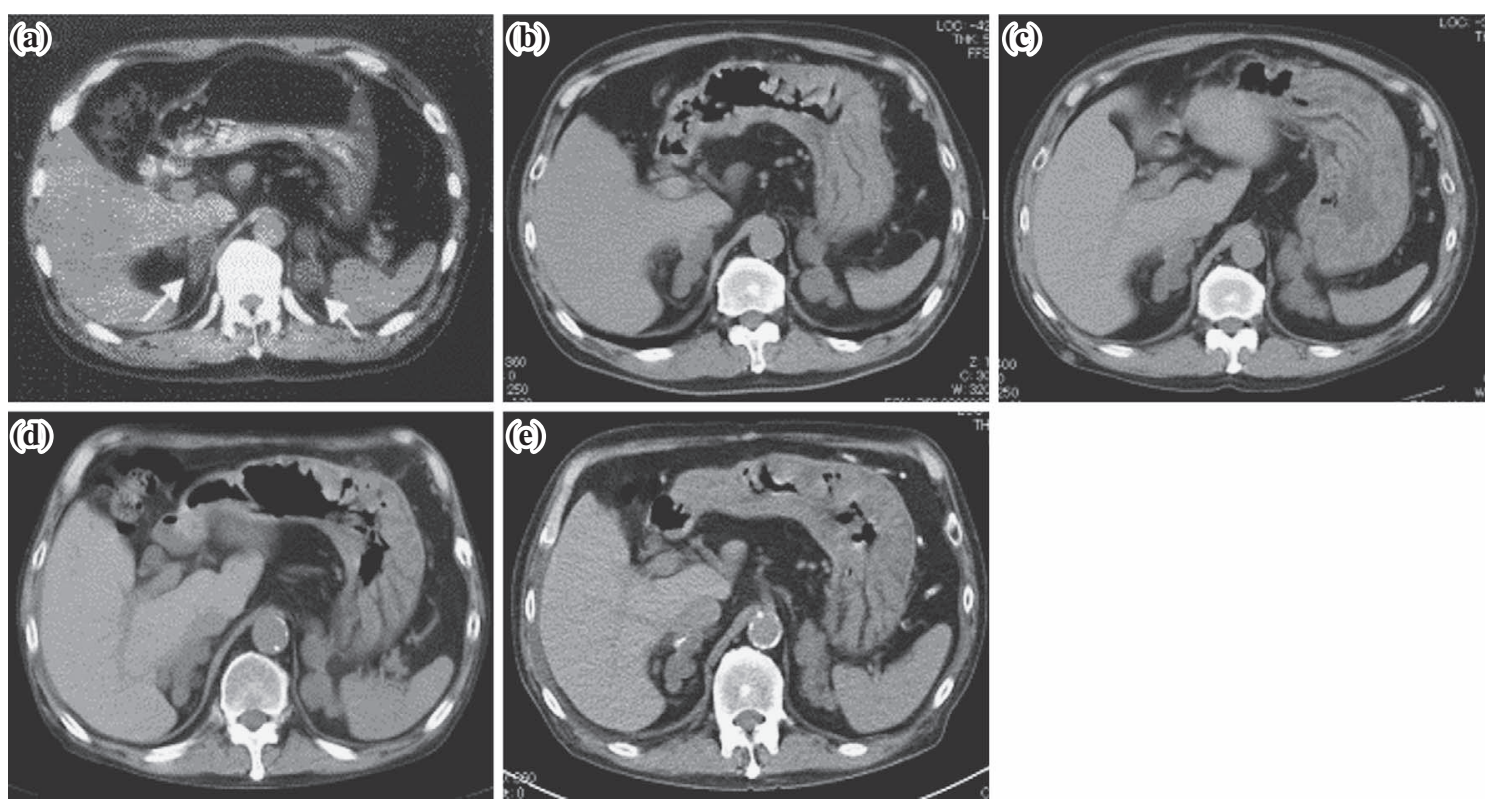

Figure 2. Abdominal CT scan images; (a)1994, (b)2000, (c)2005, (d)2007, (e)2010. Bilateral adrenal glands gradually became larger.

Table 2. Changes in Calculated Adrenal Volumes

\begin{tabular}{lcccccc}
\hline & & 1994 & 2000 & 2005 & 2007 & 2010 \\
\hline Adrenal Volumes $\left(\mathrm{cm}^{3}\right)$ & Right & 11.8 & 22.6 & 26.2 & 26.2 & 34.4 \\
& Left & 16 & 26.1 & 39 & 51.2 & 51.4 \\
& Total & 27.8 & 48.7 & 65.2 & 77.4 & 85.8 \\
\hline
\end{tabular}

The volume of each adrenal gland was calculated by assuming an ellipsoid shape as; $\pi \mathrm{abc} / 6\left(\mathrm{~cm}^{3}\right)$ (a: right - left dimension, b: anteroposterior dimension, c: upper - lower pole dimension).

nological data over 7 years are shown in Table 1. Blood samples were obtained during admission after an overnight fast and bed rest, except when assessing the diurnal rhythm of cortisol. His body mass index gradually decreased after the initiation of treatment with trilostane. There was improvement of symptoms such as a buffalo hump and skin striae within a few years, as well as gradual improvement of his moon face and central obesity. His blood pressure remained poorly control until hemodialysis was started, and it gradually improved after that. Although the plasma ACTH level was consistently suppressed, the serum cortisol level decreased and was eventually normalized after the initiation of trilostane treatment. Urinary free cortisol also showed a significant decrease, although this was partly attributed to renal dysfunction.

Changes in the size of both adrenal glands on CT scans are shown in Fig. 2. His adrenal glands gradually became larger during treatment with trilostane. We calculated the volume of each adrenal gland by assuming an ellipsoid shape as; $\pi \mathrm{abc} / 6 \mathrm{~cm}^{3}$ (a: right-left dimension, b: anteroposterior dimension, c: upper-lower pole dimension), although it was difficult to measure the dimensions precisely because of the multinodular nature of the glands. The calculated adrenal volumes increased over time despite treatment with trilostane (Table 2, Fig. 3). $\Sigma$ cortisol (the sum of four serum cortisol levels measured for examination of the diurnal rhythm) was determined as an indicator of daily cortisol secretion. The clock times of four points to measure serum cortisol were $6: 00,12: 00,18: 00$, and $24: 00$ (1994 and 2007), $6: 00,10: 00,14: 00$, and $18: 00$ (2000), and $6:$ $00,14: 00,18: 00$, and $21: 00$ (2005), respectively. Urinary free cortisol also could be a good indicator of daily cortisol secretion, but in this patient it was inappropriate because of renal dysfunction. Thus, we chose $\Sigma$ cortisol as an indicator of daily cortisol secretion to avoid the influence of renal dysfunction. $\Sigma$ cortisol was increased before 2000 and decreased slightly after the start of trilostane therapy (Fig. 3). We calculated the $\Sigma$ cortisol/adrenal volume ratio as an indicator of cortisol secretion capacity. This ratio was high before 2000, and decreased after the start of trilostane therapy (Fig. 3).

In 2011, the patient is 66 years old. He is $172 \mathrm{~cm}$ tall, weighs $60.4 \mathrm{~kg}$, and has a body mass index of 20.4. His blood pressure remains normal, even after discontinuation of all medications for hypertension. Cushingoid features, such as a moon face, central obesity, and skin striae, have markedly improved, but skin fragility and purpura persist. He remains on treatment with trilostane as an outpatient. 


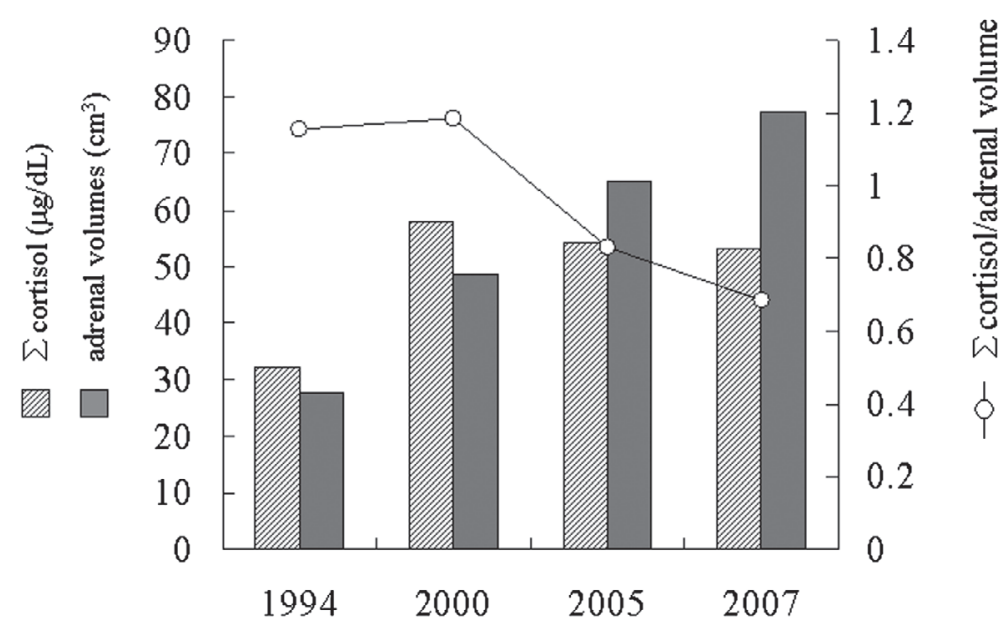

Figure 3. Changes in calculated adrenal volumes, Ecortisol (it is an indicator of daily cortisol se-

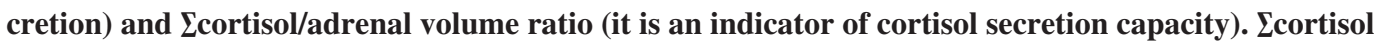
is the sum of four serum cortisol levels measured for examination of diurnal rhythm. Four points to measure serum cortisol levels were 6:00, 12:00, 18:00, and 24:00 (1994 and 2007), 6:00, 10:00, 14:00, and 18:00 (2000), 6:00, 14:00, 18:00, and 21:00 (2005), respectively. We started treatment with trilostane from 2003.

\section{Discussion}

AIMAH is characterized by bilateral macronodular hyperplasia of the adrenal glands and is one of the causes of Cushing's syndrome $(1,2,6)$. In Japan, it is a rare cause of Cushing's syndrome that occurs most frequently among middle-aged men (7). The precise etiology of AIMAH is unknown, although recent studies have demonstrated that the aberrant adrenal expression and function of one to several peptide hormone receptors, such as receptors for glucosedependent insulinotropic hormone (GIP), vasopressin, luteinzing hormone/human chorionic gonadotropin ( $\mathrm{LH} / \mathrm{hCG}$ ), beta adrenergic agonists, and serotonin, can lead to adrenal cell proliferation and abnormal regulation of steroidogenesis in AIMAH $(2,8-10)$.

Bilateral total adrenalectomy and lifetime steroid hormone replacement is the standard treatment for Cushing's syndrome due to AIMAH (2-4). We previously performed subtotal adrenalectomy in a patient with AIMAH and subclinical Cushing's syndrome, which successfully achieved normalization of the cortisol and ACTH levels without the need for steroid replacement therapy (11). There have been several other reports of subtotal or unilateral adrenalectomy in patients with subclinical Cushing's syndrome due to AIMAH (12-15). However, there have been no reports on the long-term medical treatment of Cushing's syndrome due to AIMAH. The present patient refused surgery, so we tried trilostane as an alternative treatment. Trilostane inhibits the synthesis of cortisol by competitive and reversible blocking of $3 \beta$-HSD (5). There has only been one report on the use of trilostane for AIMAH (16). Moreover, there have only been a few reports discussing the treatment of AIMAH with mitotane (17) or metyrapone (18), which are other inhibitors of cortisol synthesis. According to those reports, serum cor- tisol decreased with treatment, but the follow-up period was only around 10 months and they did not provide data about the size of the adrenal glands. To our knowledge, this is the first case of AIMAH with Cushing's syndrome treated medically for long period (7 years), in which changes of the adrenal glands were assessed throughout treatment.

In the present patient, the serum cortisol level was suppressed for 7 years by administration of trilostane, but enlargement of the adrenal glands was not prevented. That is not surprising because the mechanisms regulating cortisol secretion and cell proliferation in the adrenal glands are theoretically independent. As the adrenal glands gradually became larger, it was expected that the serum cortisol level would also increase in our patient, but it was possible to suppress cortisol over the long term. Our findings suggest that suppression of the cortisol level can lead to improvement of symptoms of steroid excess even if the growth of adrenal glands cannot be suppressed. Therefore, we consider that trilostane can be a useful option for the treatment of AIMAH when surgical removal cannot be performed for some reason. In order to suppress adrenal gland growth in this patient, another medication would have been needed in addition to the steroid synthesis blocker.

A possible candidate for reducing the adrenal volume would be a specific blocker of aberrantly expressed hormone receptors in the adrenal glands. In 2005, we examined whether there was aberrant adrenal expression of the GIP receptor by performing a $75 \mathrm{~g}$ oral glucose tolerance test. The serum cortisol level did not increase after glucose loading, suggesting that there would be no expression of receptors for food-dependent hormones, such as GIP, in the present patient. However, we did not examine the expression of other peptide hormone receptors, such as receptors for vasopressin, LH/hCG, beta adrenergic agonist, and serotonin. The precise mechanism causing cell proliferation and corti- 
sol hypersecretion remains uncertain in this patient, as in most cases of AIMAH. Serum cortisol levels, which were measured at his outpatient visits in the midmorning or early afternoon, fluctuated from about $15 \mu \mathrm{g} / \mathrm{dL}$ to $25 \mu \mathrm{g} / \mathrm{dL}$ over the 7 years (Fig. 1). These values tended to be higher than those measured in the early morning during admission (Table 1), which suggested that unknown stimulators other than ACTH or glucose could influence this fluctuation of serum cortisol level. Recently, attempts have been made to treat AIMAH with blockers of several hormone receptors, which could be related to the growth of the adrenal glands and cortisol hypersecretion (19-22). Oki et al reported a patient with subclinical Cushing's syndrome due to AIMAH who was successfully treated with the $\beta$-blocker propranolol, and achieved suppression of cortisol hypersecretion for 24 months with no change in adrenal gland size after that period (23). However, there have been no reports of patients with overt Cushing's syndrome due to AIMAH who were treated with hormone receptor blockers over a long period and the effect on the size of the adrenal glands. To clarify whether one or multiple hormone receptor blockers can be effective for AIMAH, the accumulation of more cases is necessary.

In conclusion, we reported the first case of Cushing's syndrome due to AIMAH in which treatment with trilostane was carried out for as long as 7 years. Trilostane inhibits cortisol synthesis by blocking $3 \beta-\mathrm{HSD}$, and in this patient it reduced the serum cortisol concentration and symptoms of steroid excess for a long period, although it could not suppress the growth of the adrenal glands. Trilostane can be a potential option for the treatment of AIMAH.

The authors state that they have no Conflict of Interest (COI).

\section{References}

1. Kirschner MA, Powell RD, Lipsett MB. Cushing's syndrome: nodular cortical hyperplasia of adrenal glands with clinical and pathological features suggesting adrenocortical tumor. J Clin Endocrinol Metab 24: 947-955, 1964.

2. Lacroix A, Ndiaye N, Tremblay J, Hamet P. Ectopic and abnormal hormone receptors in adrenal Cushing's syndrome. Endocr Rev 22: 75-110, 2001.

3. Lieberman SA, Eccleshall TR, Feldman D. ACTH-independent massive bilateral disease (AIMBAD): a subtype of Cushing's syndrome with major diagnostic and therapeutic implications. Eur $\mathbf{J}$ Endocrinol 131: 67-73, 1994.

4. Stratakis CA, Kirschner LS. Clinical and genetic analysis of primary bilateral adrenal diseases (micro- and macronodular disease) leading to Cushing syndrome. Horm Metab Res 30: 456-463, 1998.

5. Komanicky P, Spark RF, Melby JC. Treatment of Cushing's syndrome with trilostane (WIN 24,540), an inhibitor of adrenal steroid biosynthesis. J Clin Endocrinol Metab 47: 1042-1051, 1978.

6. Ohashi A, Yamada Y, Sakaguchi K, Inoue T, Kubo M, Fushimi H. A natural history of adrenocorticotropin-independent bilateral ad- renal macronodular hyperplasia (AIMAH) from preclinical to clinically overt Cushing's syndrome. Endocr J 48: 677-683, 2001.

7. Aiba M, Hirayama A, Iri H, et al. Adrenocorticotropic hormoneindependent bilateral adrenocortical macronodular hyperplasia as a distinct subtype of Cushing's syndrome. Enzyme histochemical and ultrastructural study of four cases with a review of the literature. Am J Clin Pathol 96: 334-340, 1991.

8. Mircescu H, Jilwan J, N'Diaye N, et al. Are ectopic or abnormal membrane hormone receptors frequently present in adrenal Cushing's syndrome? J Clin Endocrinol Metab 85: 3531-3536, 2000.

9. Bertagna X, Groussin L, Luton JP, Bertherat J. Aberrant receptormediated Cushing's syndrome. Horm Res 59: 99-103, 2003.

10. Lacroix A, Baldacchino V, Bourdeau I, Hamet P, Tremblay J. Cushing's syndrome variants secondary to aberrant hormone receptors. Trends Endocrinol Metab 15: 375-382, 2004.

11. Yamada Y, Sakaguchi K, Inoue T, et al. Preclinical Cushing's syndrome due to adrenocorticotropin-independent bilateral adrenocortical macronodular hyperplasia with concurrent excess of glucoand mineralocorticoids. Intern Med 36: 628-632, 1997.

12. Wada $\mathrm{N}$, Kubo $\mathrm{M}$, Kijima $\mathrm{H}$, et al. Adrenocorticotropinindependent bilateral macronodular adrenocortical hyperplasia: immunohistochemical studies of steroidogenic enzymes and postoperative course in two men. Eur J Endocrinol 134: 583-587, 1996.

13. Kageyama Y, Ishizaka K, Iwashina M, Sasano H, Kihara K. A case of ACTH-independent bilateral macronodular adrenal hyperplasia successfully treated by subtotal resection of the adrenal glands: four-year follow-up. Endocr J 49: 227-229, 2002.

14. Lamas C, Alfaro JJ, Lucas T, Lecumberri B, Barceló B, Estrada J. Is unilateral adrenalectomy an alternative treatment for ACTHindependent macronodular adrenal hyperplasia? Long-term followup of four cases. Eur J Endocrinol 146: 237-240, 2002.

15. Iacobone M, Albiger N, Scaroni C, et al. The role of unilateral adrenalectomy in ACTH-independent macronodular adrenal hyperplasia (AIMAH). World J Surg 32: 882-889, 2008.

16. Okada M, Kamiya Y, Jinno Y, Kato N, Kawaguchi M, Fujinami T. Cushing's syndrome caused by bilateral adrenocortical macronodular hyperplasia was succesfully treated with Trilostane. Clin Endocrinol 46: 97-100, 1998 (in Japanese).

17. Nagai M, Narita I, Omori K, Komura S, Arakawa M. Adrenocorticotropic hormone-independent bilateral adrenocortical macronodular hyperplasia treated with mitotane. Intern Med 38: 969-973, 1999.

18. Omori N, Nomura K, Omori K, Takano K, Obara T. Rational, effective metyrapone treatment of ACTH-independent bilateral macronodular adrenocortical hyperplasia (AIMAH). Endocr J 48: 665-669, 2001.

19. Reznik Y, Allali-Zerah V, Chayvialle JA, et al. Food-dependent Cushing's syndrome mediated by aberrant adrenal sensitivity to gastric inhibitory polypeptide. N Engl J Med 327: 981-986, 1992.

20. Daidoh $\mathrm{H}$, Morita $\mathrm{H}$, Hanafusa $\mathrm{J}$, et al. In vivo and in vitro effects of AVP and V1a receptor antagonist on Cushing's syndrome due to ACTH-independent bilateral macronodular adrenocortical hyperplasia. Clin Endocrinol (Oxf) 49: 403-409, 1998.

21. Lacroix A, Tremblay J, Rousseau G, Bouvier M, Hamet P. Propranolol therapy for ectopic beta-adrenergic receptors in adrenal Cushing's syndrome. N Engl J Med 337: 1429-1434, 1997.

22. Lacroix A, Hamet P, Boutin JM. Leuprolide acetate therapy in luteinizing hormone--dependent Cushing's syndrome. N Engl J Med 341: 1577-1581, 1999.

23. Oki K, Yamane K, Nakanishi S, Nakashima R, Jitsuiki K, Kohno $\mathrm{N}$. Improvement of hypercortisolism by $\beta$-blocker therapy in subclinical Cushing's syndrome associated with ACTH-independent macronodular adrenocortical hyperplasia. Endocrine 36: 372-376, 2009.

(C) 2011 The Japanese Society of Internal Medicine http://www.naika.or.jp/imindex.html 